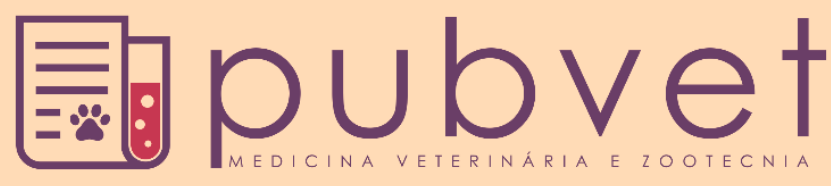

https://doi.org/10.31533/pubvet.v15n09a921.1-4

\title{
Ceratose liquenóide em cães: características e diagnóstico de uma enfermidade raramente relatada na medicina veterinária
}

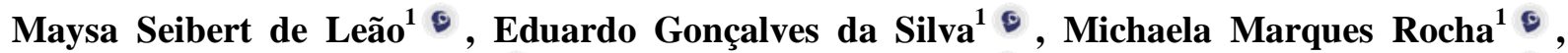 \\ Caroline Castagnara Alves ${ }^{1}{ }^{\bullet}$, Francesca Lopes Zibetti $^{1} \bullet$, Daniele Weber Fernandes ${ }^{1}{ }^{\circ}$, \\ Thaíssa Gomes Pellegrin $^{1} \bullet$, Brenda Madruga Rosa ${ }^{1} \bullet$, Amanda Leal de Vasconcellos ${ }^{2}{ }^{\ominus}$, Paula \\ Priscila Correia $\operatorname{Costa}^{3} 0$
}

${ }^{l}$ Graduando de Medicina Veterinária, Universidade Federal de Pelotas, Pelotas-RS, Brasil

${ }^{2}$ Professor da Universidade Estadual do Ceará, Departamento de Clínicas Veterinárias, Fortaleza-CE, Brasil

${ }^{3}$ Professor da Universidade Federal de Pelotas, Departamento de Clínicas Veterinárias, Pelotas-RS, Brasil

*Autor para correspondência, E-mail: carol090898@gmail.com

\begin{abstract}
Resumo. A ceratose liquenóide é uma enfermidade cutânea pouco relatada e que ainda possui pouco estudo em Medicina Veterinária. Essa enfermidade pode acometer cães adultos de forma idiopática, causando lesões solitárias, alopécicas e não pruriginosa no pavilhão auricular, axilas e virilhas de cães adultos. Frequentemente as lesões desaparecem espontaneamente, dificultando o diagnóstico dessa enfermidade, que é realizado de acordo com as características macroscópicas das lesões cutâneas e análises histopatológicas. O objetivo desta revisão de Literatura é caracterizar as lesões causadas por essa enfermidade e a realização do seu diagnóstico, assim como seu diagnóstico diferencial.
\end{abstract}

Palavras chave: Caninos, histopatologia, lesão cutânea

\section{Lichenoid keratosis in dogs: characteristics and diagnosis of a related disease in veterinary medicine}

\begin{abstract}
Lichenoid keratosis is a skin disease that is little reported and still has little study in Veterinary Medicine. This disease can affect adult dogs in an idiopathic way, causing solitary, alopecic and non-itchy lesions in the ears, underarms and groins of adult dogs. The lesions often disappear spontaneously, making it difficult to diagnose this disease, which is performed according to the macroscopic characteristics of the skin lesions and histopathological analyzes. The purpose of this literature review is to characterize the injuries caused by this disease and the realization of its diagnosis, as well as its differential diagnosis.
\end{abstract}

Keywords: Canines, histopathology, skin lesion

\section{Introdução}

A ceratose liquenóide (CL) é uma enfermidade cutânea raramente relatada em cães. Essa doença se assemelha a uma enfermidade da pele humana, denominada de "ceratose liquenóide benigna (Souza et al., 2009). Normalmente assume a forma de lesões únicas em pina, podendo também afetar as axilas e virilha de cães adultos. As lesões se caracterizam por ser circunscritas, eritematosas, escamosas. Além disso, estão associadas à formação de placas hiperceratóticas ou papilomas, variando de 0,5 a $2 \mathrm{~cm}$ de diâmetro (Miller et al., 2013). Não há predisposição de raça ou sexo e a etiologia dessa condição é desconhecida. 
As lesões de ceratose liquenóide que ocorrem na virilha e axilas devem ser diferenciadas dos papilomas de acantose e da dermatose psoriasiforme liquenóide. $\mathrm{O}$ aparecimento de lesões no pavilhão auricular pode auxiliar na diferenciação da ceratose liquenóide com essas enfermidades (Patnaik et al.. 1984; Poggiani et al., 2012).

O diagnóstico é baseado nas características macroscópicas das lesões cutâneas associadas à histopatologia. Histologicamente, pode-se observar grande quantidade de linfócitos e plasmócitos na junção derme epidérmica, que podem invadir a epiderme, da mesma forma que ocorre na dermatose liquenóide e na micose fúngica.

As medidas terapêuticas incluem a excisão cirúrgica das lesões ou observação do quadro clínico, sem tratamento concomitante (Miller et al., 2013). O prognóstico da ceratose liquenóide é favorável, e a maioria dos casos desaparece espontaneamente (Patnaik et al., 1984; Poggiani et al., 2012).

\section{Aspectos estruturais da pele}

A pele é o maior órgão do corpo, reunindo muitas funções essenciais do organismo, como proteção, regulação da temperatura e produção de vitamina D. Essa estrutura pode ser dividida em duas camadas principais, a epiderme e a derme, mas também devemos considerar tecido subcutâneo e apêndices (folículos pilosos, glândulas sebáceas, glândulas sudoríparas) (Zachary et al., 2012).

A epiderme, porção mais externa da pele, composta por múltiplas camadas de células, é onde podem ser observadas alterações histológicas. A divisão mais superficial é chamada de estrato córneo e é caracterizada pela presença de células queratinizadas e achatadas, os corneócitos, que constantemente se desprendem. Portanto, temos a camada granular, constituída por células degeneradas com grânulos de querato hialino, corando basofilicamente. Essas duas camadas podem ser separadas por células completamente queratinizadas, o estrato lúcido, que é mais bem visualizado nas almofadas de cães e gatos. Mais profundamente, está o estrato espinhoso composto de células poliédricas conectadas entre si por desmossomos. Finalmente, existe o estrato basal, ou camada germinativa, formado por uma linha de células cuboidais apoiadas em uma membrana basal. Esta porção também é observada em melanócitos, células de Langerhans e células de Merkel (Miller et al., 2013; Zachary et al., 2012).

A derme consiste em fibras de colágeno e elásticas e substância amorfa; tem como função nutrir e apoiar a epiderme. A derme superficial adapta-se ao contorno da pele e mantém a porção superior do folículo piloso e das glândulas sebáceas, constituindo-se de fibras finas de colágeno. A camada dérmica profunda sustenta a porção inferior do folículo piloso e as glândulas apócrinas, consistindo em feixes de colágeno maiores que a superfície. Na derme normal encontram-se linfócitos, mastócitos, células plasmáticas, macrófagos e, raramente, eosinófilos e neutrófilos, que se concentram em torno de pequenos vasos superficiais (Miller et al., 2013; Zachary et al., 2012).

\section{Etiopatogenia}

A ceratose liquenóide é uma doença cutânea raramente relatada em cães. Há evidências de que essa condição é semelhante a uma doença comum da pele humana, conhecida como "ceratose liquenóide benigna" (Souza et al., 2009). Na maioria dos casos, os cães afetados são adultos, e de acordo com a literatura, parece haver uma predileção por raça ou sexo na etiologia da doença (Anderson et al., 1989), ao contrário do que ocorre na doença de pele humana, em que as lesões ocorrem predominantemente no tronco e extremidades superiores e as mulheres de meia-idade são mais afetadas (Kim et al., 2013; Kim et al., 2015). A doença é idiopática em animais, mas a condição em humanos foi associada a áreas expostas ao sol (Goette, 1980).

\section{Sinais clínicos}

Clinicamente, a ceratose liquenóide é caracterizada pelo surgimento de lesões solitárias, alopécicas, não pruriginosas, bem circunscritas na forma de nódulos, pápulas ou como placas hiperceratóticas ou papilomatose (verrucosa), geralmente eritematosa ou marrom-clara, escamosa, que normalmente atinge um diâmetro de 0,5 a $2 \mathrm{~cm}$ (Muller et al., 2013; Souza et al., 2009). Frequentemente, essas lesões regridem espontaneamente (Morgan et al., 2005). As lesões afetam principalmente a pele da parte 
interna do pavilhão auricular e virilha, mas também podem afetar as axilas (Figura 1) (Souza et al., $\underline{2009)}$.

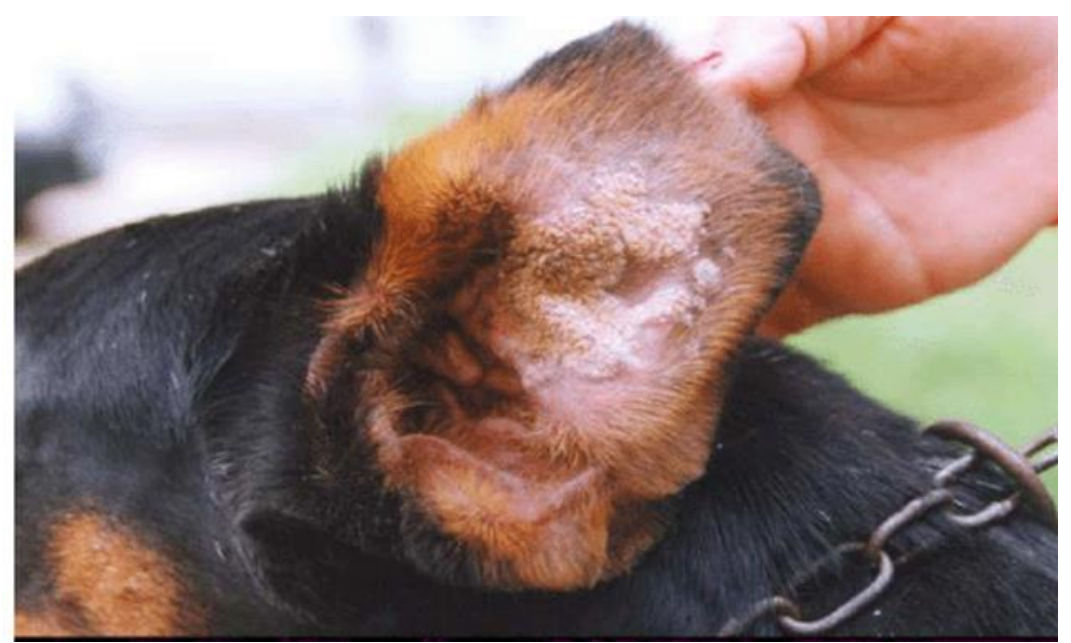

Figura 1. Ceratose liquenóide na pele de um cão macho, raça Dobermann. Placas verrucosas, marrom claro, multifocal na superfície interna da orelha esquerda (Souza et al., 2009).

\section{Diagnóstico}

Para o diagnóstico de ceratose liquenóide deve-se considerar uma combinação de manifestações clínicas e achados histopatológicos. As biópsias excisionais são recomendadas para placas solitárias e, se estiverem presentes na pina, deve-se cuidar para não danificar a frágil cartilagem subjacente (Gross et al., 2008). Gross et al. (2008) caracterizaram a lesão histologicamente pela observação de epiderme irregularmente acantótica e, em alguns casos, com hiperplasia psoriasiforme acentuada. Geralmente há hiperceratose difusa e paraqueratose multifocal, variavelmente severa e hipergranulose, devido ao aumento da espessura da camada granular. Outras características incluem crostas e pústulas intradérmicas. Pode-se observar também extensa infiltração celular por linfócitos e plasmócitos na junção dermoepidérmica (Figura 2), que pode invadir a epiderme, semelhante a casos de dermatose liquenóide e doenças fúngicas (Souza et al., 2009).

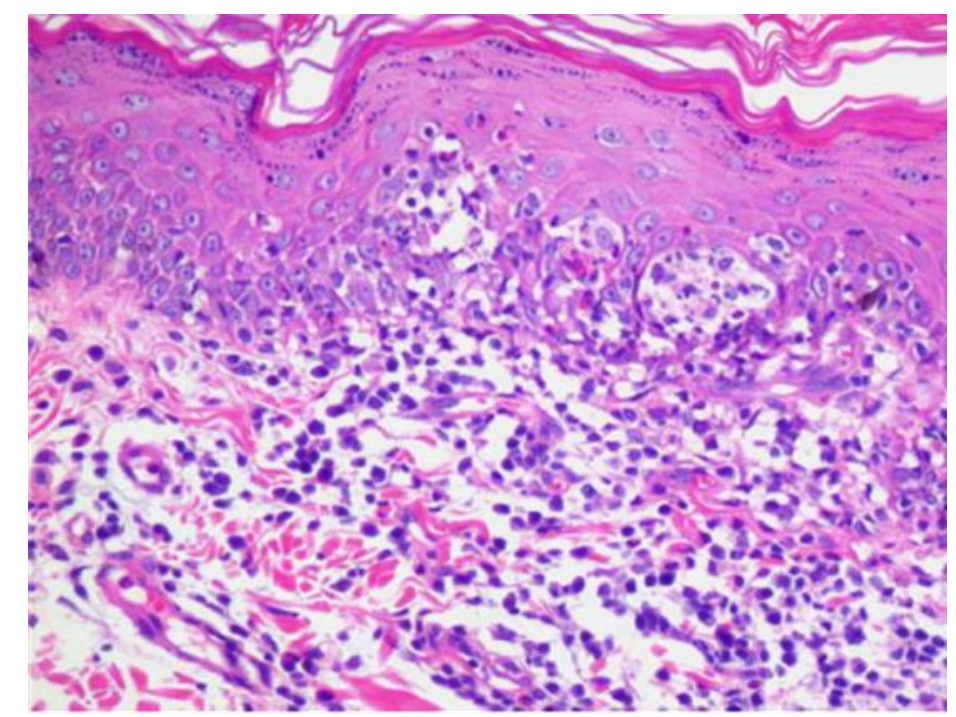

Figura 2. Ceratose liquenóide na pele de um cão, raça Dobermann. Infiltrado inflamatório denso que oblitera a junção derme epidérmica, aspecto típico da dermatite liquenóide. $\mathrm{O}$ infiltrado inflamatório consiste principalmente em pequenos linfócitos não clivados e em quantidade moderada de células plasmáticas. Observar o intenso epiteliotropismo, acúmulos de linfócitos entre os queratinócitos na epiderme acantótica e grandes cavidades bolhosas subepidérmicas parcialmente preenchidas por linfócitos e alguns neutrófilos degenerados (Souza et al., 2009). 


\section{Diagnóstico diferencial}

Clinicamente, as lesões de ceratose liquenóide que ocorrem na virilha devem ser diferenciadas de papilomas, acantose nigricante e dermatose liquenóide. O envolvimento das orelhas pode auxiliar nessa diferenciação, assim como outras doenças (Souza et al., 2009). Histologicamente, outra patologia importante deve ser considerada como diferencial, a dermatose liquenóide psoriasiforme, mas esta é mais comumente encontrada em cães de raça Springer Spaniel (Gross et al., 2005).

\section{Tratamento}

O prognóstico da ceratose liquenóide é favorável com regressão espontânea na maioria dos casos (Anderson et al., 1989). Quando isso não ocorre, a melhor indicação terapêutica é a excisão cirúrgica com posterior observação a esse tratamento (Muller et al., 2013).

\section{Considerações finais}

A ceratose liquenóide é uma doença de pele pouco estudada na medicina veterinária, embora seja reconhecida há muitos anos em cães. Embora incomum, a ceratose liquenoide reúne características únicas que permitem uma suspeita clínica fundamentada e um fácil diagnóstico histológico. Além disso, essa condição não afeta seriamente a saúde do animal, obtendo um prognóstico favorável.

A falta de informações sobre esta enfermidade envolve diversos fatores, principalmente as raras ocorrências na prática clínica, sendo pouco relatada na literatura até o momento. Porém, outros fatores podem estar relacionados a essa doença, como o diagnóstico incorreto e o atraso do diagnóstico, uma vez que as lesões costumam regredir espontaneamente, não permitindo uma melhor avaliação do caso.

\section{Referências bibliográficas}

Anderson, W. I., Scott, D. W., \& Luther, P. B. (1989). Idiopathic benign lichenoid keratosis on the pinna of the ear in four dogs. The Cornell Veterinarian, 79(2), 179-184.

Goette, D. K. (1980). Benign lichenoid keratosis. Archives of Dermatology, 116(7), 780-782.

Gross, T. L., Ihrke, P. J., Walder, E. J., \& Affolter, V. K. (2008). Skin diseases of the dog and cat: clinical and histopathologic diagnosis. John Wiley \& Sons.

Kim, H. S., Park, E. J., Kwon, I. H., Kim, K. H., \& Kim, K. J. (2013). Clinical and histopathologic study of benign lichenoid keratosis on the face. The American Journal of Dermatopathology, 35(7), 738741.

Kim, M. S., Ha, J. M., Cho, E. B., Park, E. J., Kim, K. H., \& Kim, K. J. (2015). Porokeratosis presenting with a benign lichenoid keratosis-like appearance. Annals of Dermatology, 27(6), 778-779.

Miller, W. H., Griffin, C. E., Campbell, K. L., \& Muller, G. H. (2013). Muller and Kirk's Small Animal Dermatology. Elsevier Health Sciences.

Morgan, M. B., Stevens, G. L., \& Switlyk, S. (2005). Benign lichenoid keratosis: a clinical and pathologic reappraisal of 1040 cases. The American Journal of Dermatopathology, 27(5), 387-392.

Patnaik, A. K., Ehler, W. J., \& MacEwen, E. G. (1984). Canine cutaneous mast cell tumor: morphologic grading and survival time in 83 dogs. Veterinary Pathology, 21(5), 469-474.

Poggiani, S. S. C., Terra, E. M., Torres Neto, R. T., Costa, M. T., \& Amorim, R. L. (2012). Canine cutaneous mast cell tumor: biologic behavior and its correlation with prognostic indicators. Open Journal of Veterinary Medicine, 2(4), 255-261. https://doi.org/10.4236/ojvm.2012.24041.

Souza, T. M., Fighera, R. A., Schmidt, C., \& Barros, C. S. L. (2009). Ceratose liquenóide em um cão. Ciência Rural, 39, 937-940.

Zachary, J. F., McGavin, D., \& McGavin, M. D. (2012). Bases da patologia em veterinária. Elsevier Brasil.

Histórico do artigo:

Recebido: 14 de abril de 2021

Aprovado: 1 de junho de 2021
Licenciamento: Este artigo é publicado na modalidade Acesso Aberto sob a licença Creative Commons Atribuição 4.0 (CC-BY 4.0), a qual permite uso irrestrito, distribuição, reprodução em qualquer meio, desde que o autor e a fonte sejam devidamente creditados. 